\title{
Thoughts of death disrupt foresight: the 'ostrich bias'
}

Stefania de Vito ${ }^{1, *}$, Maria A. Neroni ${ }^{2}$, Jean-François Bonnefon ${ }^{3}$, Sergio Della Sala $^{4}$, Alessandra Capuozzo ${ }^{5}$, Denis A. Engemann ${ }^{6}$, Maria A. Brandimonte ${ }^{5}$

1Department of Letters, Language, Human Science \& Society (LLSHS), Université Paris 13, France

${ }^{2}$ Department of Engineering, Engineering Design Centre, University of Cambridge, UK

${ }^{3}$ Toulouse School of Economics, Institute for Advanced Study in Toulouse, Center for Research in Management, University of Toulouse, France ${ }^{4}$ Human Cognitive Neuroscience, Psychology, University of Edinburgh, UK ${ }^{5}$ Laboratory of Experimental Psychology, Suor Orsola Benincasa University, Naples, Italy ${ }^{6}$ Parietal project-team, INRIA Saclay, Île de France, France

Running head: Thoughts of death disrupt foresight

*Corresponding author:

Stefania de Vito

\section{LLSHS}

99 Avenue Jean Baptiste Clément

93430 Villetaneuse

France

Email: stdevit@gmail.com 


\begin{abstract}
Humans have a predilection for optimistic personal scenarios when thinking of their future. They tend not to project stressful episodes into the future and are inclined to repress the idea of their vulnerability, to an extent that, when explicitly asked to think about their death, they use various cognitive strategies to deny it. In this study, we investigated the specific coping persons can use when required to construct personal future scenarios after imagining their own death. Our participants were asked to describe in details first the moment of their own's death and then past and future personal events. We observed a selective reduction in specificity, but not in accessibility, of future simulations, whereas past episodes were normally re-constructed in all the conditions. We named this effect the 'ostrich bias'. We interpreted it as a protective behaviour against future thoughts that could possibly direct toward an inescapable mental threat.
\end{abstract}

Keywords: Future thinking, mortality salience, terror management theory, ostrich bias, future simulations. 


\section{Introduction}

When individuals recall important personal events from their past, they list about $35 \%$ of negative episodes such as stressful times, illness, and death; whereas these categories only account for less than $2 \%$ of the important events they imagine in the future, with death being totally absent (Berntsen \& Bohn, 2010). In this article, we investigated whether there is a special reason for individuals not to imagine their future death, over and beyond the fact that they do not like to imagine negative future events.

One reason persons do not like to imagine negative future events is that mental simulation is associated with the subjective belief that the imagined event will materialise in the future (Ernst \& D’Argembeau, 2017; Sherman et al., 1985; Szpunar \& Schacter, 2013; Taylor \& Schneider, 1989; de Vito, Gamboz \& Brandimonte, 2012a). Such feeling can be pleasant for positive events, but can result in an aversive experience for negative events. Therefore, individuals prefer to imagine desirable rather than undesirable future events (Berntsen \& Jacobsen, 2008) and to focus on more optimistic scenarios (Newby-Clark et al., 2000). Accordingly, desirable future events are more vividly and easily imagined, richer in episodic details, and set in a clearer spatio-temporal frame than undesirable scenarios (D’Argembeau \& Van der Linden, 2004; de Vito et al., 2015a). Similarly, negative cues and strategies to avoid scaring events can decrease the specificity of future thoughts (Jumentier, Barsics, \& Van der Linden, 2017). However, death is somewhat special in that respect, being already certain. Thinking about one's future death cannot increase its probability.

This fact was recently emphasised in the argument that individuals do not imagine their future death because they do not need to. Indeed, the function of prospective thinking is to simulate multiple versions of future events to guide current decisions and action (de Vito \& Della Sala, 2011; Kant, 1798; Neroni, Gamboz \& Brandimonte, 2014; Addis, Wong \& Schacter, 2008). Because there is 
ultimately nothing that can be done to avoid death, the pragmatic homo prospectus does not waste time and cognitive resources to think about it and efficently prefers to tackle rather achievable objectives (Seligman et al., 2016).

On the contrary, in this article we suggest that persons do not want to think of their future death, because doing so would impair their prospective thinking. More specifically, we hypothesise that individuals proactively avoid thinking about their future death, and that the defensive strategy they trigger to do so blurs their prospective thinking in a way that affects their simulation of other, non death-related events. We name this effect the ostrich bias. Like ostriches we metaphorically bury our heads in sand and we do it to neglect danger.

This hypothesis is in line with the Terror Management Theory, which posits that individuals have a strong motivation not to think about their own death, and use an array of cognitive defenses to suppress thoughts of death when they occur (Greenberg, Pyszczynski, \& Solomon, 1986). For example, individuals who are prompted to think about their own death show impaired performance on a variety of tasks that require executive function (Greenberg, Pyszczynski, \& Solomon, 1986). The aim of these experiments is to show that when individuals are prompted to think about their future death, an impairment is observed on tasks whose contents are not related to death — and this impairment is considered the signature of a costly cognitive defense against death related thoughts. Since an active dismissal of thoughts of death from consciousness relies on cognitive resources, the effect of mortality salience on subsequent tasks is comparable to a very high cognitive load (Trémolière, De Neys, \& Bonnefon, 2012; Burke, Martens, \& Faucher, 2010).When reminded of their mortality, the induced depletion of cognitive resources has as consequence that individuals are less likely to give utilitarian responses to moral conflicts (Trémolière, De Neys, \& Bonnefon, 2012) and show an impaired performance on the belief bias task (Trémolière, De Neys, \& Bonnefon, 2014), on the Stroop task and on reasoning tasks (Gailliot, Schmeichel, \& Baumeister, 2006). In a 
mirror pattern, when a cognitive load manipulation is added to a mortality salience condition to deny access to cognitive resources, individuals display a facilitated access to death-related thoughts (Arndt et al., 1997).

There is also a clear evidence that a variety of cognitive biases can be used to defend oneself against threatening death-related thoughts (Ditto, Jemmot, \& Darley, 1988). These cognitive biases are used in particular when thinking about the future. Self-serving biases help humans to maintain their belief that good things will happen to them and bad things will not. Persons tend to expect positive future events even when there is no evidence to sustain such expectations (Optimistic Bias, Leopardi, 1831-1832; Sharot et al., 2007). For example, there is a tendency to believe that one own's life will be longer and healthier than average (Weinstein, 1980). Moreover, in the attempt to provide evidence to such expectations, individuals tend selectively to hold theories that are consistent with their optimistic bias (Kunda, 1987).

In the present study, we capitalise on previous work to explore whether individuals do not think about their future death because they do not need to, and thus increase the efficiency of their prospective thinking (Seligman et al., 2016), or whether they do not think about their future death because they do not want to, and are ready to impair their prospective thinking to do so.

The key to this comparison is to ask persons to think about their own future death for a while (a classic "mortality salience" manipulation; Greenberg, Pyszczynski, \& Solomon, 1986), and then to ask them to mentally simulate a past or a future event of their choice. The participants should show a specific impairments in the simulation of future events only in case that thinking about death represents a problem for them, something that they try to avoid. We use three categories of indicators to characterise the simulation of these events: mental availability, episodic specificity, and self-reported qualitative experience. Furthermore, we use three control conditions to establish the specific effect of the mortality salience manipulation: a condition in which participants think 
about another person's death (i.e., their favourite celebrity), a condition in which participants imagine their own birth, and a condition in which they imagine an episode of intense anger.

\section{Method}

\section{Participants}

Eighty-eight young healthy participants entered this experiment ( 80 females; mean age $=19.90$, SD =3.21). They were recruited as volunteers at Suor Orsola Benincasa University, in Naples (Italy). No participant had a history of neurological or psychiatric disorders. Before starting the testing session, participants signed an informed consent form. The following data exclusion criteria were applied. We considered producing at least three sentences as minimally serious engagement with the task. Consequently, we excluded data from 6 participants. The study procedures were approved by the local ethical committee.

\section{Materials and Procedure}

Testing was carried out in a single session. All participants were tested individually and sat facing the same experimenter in a quiet testing environment. Participants were initially briefed that they would be required to remember, imagine, and describe various events and to rate their characteristics.

Mortality salience manipulation. Prior to engaging with the main task, participants were asked to imagine and describe in details one of four different, randomly assigned events in a between-subject design: (a) own death, (b) another person's death, (c) own birth, (d) a future personal episode causing intense anger. More specifically, the "own death" scenario represented the experimental condition, which required participants to imagine the moment of their own death ("Describe the moment of your death using as many details as you can. What do you think will happen physically to you while dying and once you are dead"). The other scenarios served us as control conditions. We intended to control for three variables that could potentially affect our outcomes. We wanted to make sure that the effect on the dependent variable was due to the imagination of their own death, and not to: (a) a general thought of death; (b) the imagination of a meaningful and realistic personal event of which one cannot have direct memories (e.g., their own birth); (c) the imagination of a very emotional, negative personal event (e.g., intense anger). To control for each of these potential disturbances, participants were requested to imagine: (a) "someone else's death", i.e., the death of a 
famous person ("Describe the death of your favourite celebrity with as many details as possible. What you think will it happen to him or her physically while he or she is dying and once he or she is physically dead"); (b) the moment of "their own birth" ("Describe the moment of your birth using as many details as you can. What do you think did it happen to you physically while your mother was giving birth to you, and what do you think happened to you once you were born"); (c) and finally, a situation in which they could feel intensely angry ("Describe a possible situation, in which you can feel anger using as many details as you can. What do you think will it happen to you physically while you are angry and what will happen to you physically soon after"). Participants in all groups were also required specifically to describe their anticipatory emotions (i.e., emotions experienced in the present while thinking of a future event; Barsics, Van der Linden, \& D'Argembeau, 2016) related to all these preliminary events: "Describe briefly what you felt while you were thinking about your death / the death of your favourite famous person / your birth / a situation of intense anger". Participants were encouraged to imagine the event in as much detail as possible, including such aspects as setting, objects or persons present, actions, as well as any colours, smells, tastes, sounds, emotions and thoughts that would be elicited. There was not a time limit to describe the event.

Furthermore, we maintained the prompting procedure for the participants in all the experimental conditions. When participants stopped talking, the experimenter asked only once whether there was any further detail that they would like to add. The participants' descriptions were recorded digitally to enable later transcriptions and subsequent scoring of the responses. After the event description, in all the groups, participants were asked to rate the characteristics of the described scenario, on a 7point Likert scale. Specifically, the scenario was rated in terms of quantity of visual details ( $1=$ none, $7=\mathrm{a}$ lot $)$, clarity of location $(1=$ vague, $7=$ very clear $)$, clarity of the temporal connotation $(1$ = vague, $7=$ very clear $)$, overall clarity $(1=$ vague, $7=$ very clear $)$, subjective experience associated with the mental image $(1=$ none, $7=\mathrm{a}$ lot $)$, and emotional valence $(1=$ extremely positive, $7=$ extremely negative). Furthermore, participants were asked to indicate (a) how often they had experienced in the past the same or a similar event $(1=$ never; $7=$ very often $)$, and (b) how often they had imagined in the past the same or a similar event $(1=$ never, $7=$ very often $)$.

Past and future thinking. Soon after describing and rating the characteristics of one of the four preliminary events, participants were invited to remember past autobiographical events and to imagine future personal episodes, with two different tasks: Autobiographical Fluency and Cueing. 
The order of the presentation of the tasks was counterbalanced across participants. The participants' responses were recorded digitally to enable later transcriptions and subsequent scoring.

Autobiographical Fluency Task: generic accessibility of temporal representations. With the Autobiographical Fluency task we intended to explore whether thinking of one's own death hampers the access to the personal future, by reducing the quantity of generic representations of the future that come to mind. The experimental procedure for the Autobiographical Fluency task was adapted from D'Argembeau et al. (2010) and Neroni et al. (2016). Participants were instructed to list, in one minute, as many representations as possible that happened to them in the past/might happen to them in the future. Each participant was assigned to a counterbalanced version of the task with the constraint that half participants performed the past version of the task first, followed by the future version of the task, and the other half received the opposite sequence. Participants were instructed that the events could refer to trivial or important episodes; they could be associated to intentional thoughts or thoughts that come spontaneously to mind; they could be related to positive, neutral or negative events; they could refer to recent or more remote future and past. Future events had also to be plausible, given the participant's plans, and novel, i.e., not previously experienced by the participant. After one minute, a bell rang to indicate the end of the task.

The total number of events described in both the past and future versions was considered. A rater who was blind to the hypotheses of the study classified each event reported during the task as referring to a "positive", "negative", or "neutral" event.

Cueing task: episodic specificity of temporal representations. With the Cueing task we intended to explore whether thinking of one's own death could affect the quality of personal future simulations. In this case, we aimed at investigating the extent to which individuals could populate episodic future thoughts with phenomenological details, after thinking of their own death. The experimental procedure for the Cueing task was adapted from D'Argembeau and Van der Linden, (2004) and from Addis, Wong, and Schacter (2008). Specifically, participants were asked to remember four temporally and contextually specific events (two in the past and two in the future), in response to cue words. Future events had also to be plausible, given the participant's plans, and novel, namely not previously experienced by the participant. For each participant, four cue-words were randomly selected from a larger pool including 20 words taken from the Barca, Burani and Arduino (2001) Italian norms and matched for familiarity, frequency, imageability, and concreteness. Each participant was assigned to a counterbalanced version of the task with the 
constraint that half participants performed the past version of the task first, followed by the future version of the task, and the other half received the opposite sequence. Each word was written on a card that was presented, one at a time, and remained in view for all the duration of the description. Participants were encouraged to remember/imagine the events in as much detail as possible, including such aspects as setting, objects or persons present, actions, as well as any emotions, colours, smells, tastes, or sounds that were elicited. Participants were allowed to orally illustrate the event until they thought that nothing else could be added. There was no time limit to describe each event. Participants' descriptions were digitally recorded to enable later transcriptions and subsequent scoring of the responses. After each event description, participants rated, on 7-point scales, the characteristics of the past/future event, as in the Mortality Salience Manipulation (see procedure above).

The quality of the events described by the participants during the preliminary conditions and the cue task were scored using the standardised scoring procedure developed by Levine et al. (2002) in the Autobiographical Interview. More precisely, for each scenario produced by participants, the core event was first identified. Then, the transcription was segmented into (a) internal details, i.e., informational bits indicating happenings, places, time, perceptual details, emotions/thoughts pertaining directly to the main event, and (b) external details, i.e., informational bits that were not uniquely specific to the main memory event being described and not anchored to the time and place of the main event, as general facts/knowledge related to the context of the event, details concerning unrelated events, and meta-cognitive statements. The detail subtypes within each category were summed to form, for each event, an internal and an external detail composite score. The transcriptions were segmented into internal and external details by a single trained rater, who was blind to the hypotheses of the study. This rater scored events in a manner that was highly reliable with the ratings provided by the experimenter. In case of lack of agreement, the two raters would meet and try to converge on a common score. The inter-rater reliabilities calculated on a subset of the $20 \%$ of randomly selected events, were $r=.98, p<.001$ and $r=.90, p<.001$ for internal and external details, respectively.

\section{Statistical Analysis}

All analyses were conducted using the open source programming languages Python (Version 3.52) and the R language of statistical computing (Version 3.3). To ensure reproducibility, we used scripting for computation and visualization. All custom code is available as Supplementary Material 
once the article is published. In the following we provide additional details on the different analyses techniques used throughout the present study.

Data transforms and test-statistics. For the Autobiographical Fluency task, we analysed the event counts by condition across subjects. For the Cueing task we considered the cross-trial average of the number of events for each subject. For the visualization of the highly skewed ratio of past to future internal details in Figure 2, we computed the average of the base 10 log-ratio of past to future events across subjects. This test-statistic yields an approximately symmetric distribution and hence readily supports averaging. Second, it can be intuitively mapped to the average relative change in percent by exponentiating with the base of the logarithm and then multiplying by 100 and subtracting 100 .

Non-parametric Bootstrap. For assessments of confidence intervals we employed a nonparametric multisample bootstrap (Efron \& Hastie, 2016). For each condition, samples were drawn 5000 times with replacement. Subsequently the test-statistic was computed on each perturbed version of the data. The confidence intervals were then obtained from looking up the two-sided percentiles corresponding to the 5\% significance level, i.e., 2.5 and 97.5 .

Linear mixed-effect models. To explicitly model the data we considered the linear mixed effect modeling framework proposed by Douglas Bates (Bates et al., 2014). This technique is particularly well suited for smaller samples sizes and supports to statistical control for effects related to the particular sample, hence, extending inference to the population level. In all models we considered the participant as random effects whereas the different conditions were modeled as fixed-effects. As the autobiographical fluency yielded non-normally distributed count data, i.e. the number of events, we used a Poisson generalized linear mixed effects model. For the Cueing task and the analysis of subjective experience, we used a Gaussian linear mixed effects model.

\section{Data Availability}

The datasets analysed and the code used for the analyses during the current study are available from the corresponding author on reasonable request. Once the article is accepted for publication the code to generate the figures will be shared publicly. 


\section{Results}

\section{Mortality Salience Manipulation}

Participants used more external than internal details to describe the events in the Death condition and reported different subjective experiences associated with the episodes they had to generate (See Supplementary Results concerning 'Mortality Salience Manipulation'). Unsurprisingly, our analysis revealed that the Birth condition triggered the most positive feelings, and more past events were reported in the Anger condition. Likewise, in the Anger condition, also the highest temporal definition was observed, i.e., precise ideas about the time of the episode, as well as the most intense feeling of actually experiencing the event.

\section{Past and Future Thinking}

\section{Generic accessibility of temporal representations: Autobiographical Fluency}

Figure 1 displays the average number of negative, neutral, and positive events generated in each condition during the autobiographical fluency task, separately for past and future events. Figure 1 suggests that negative events were preferentially generated for past episodes. However, the positive, neutral and negative events showed similar distributions across conditions within each temporal context. We explicitly modeled these data using a generalised linear mixed-effects approach (Bates et al., 2014) and considered four different models. To analyse the total number of events as well as the number of negative, neutral, and positive events we chose a Poisson link function. All models included participants as a random factor, Condition (reference level: Death) and Temporal Direction (reference level: Future) as fixed effects, as well as the interaction term between Condition and Temporal Direction. In line with Figure 1, the only effect detected by these analyses was an effect of Temporal Direction on the number of negative events. Participants generated more negative events in the past than in the future, $\mathrm{b}=1.85, \mathrm{SE}=0.44, \mathrm{p}<.001$. In other words, our analyses suggest that the generic availability of temporal representations was not altered by the mortality salience manipulation. 

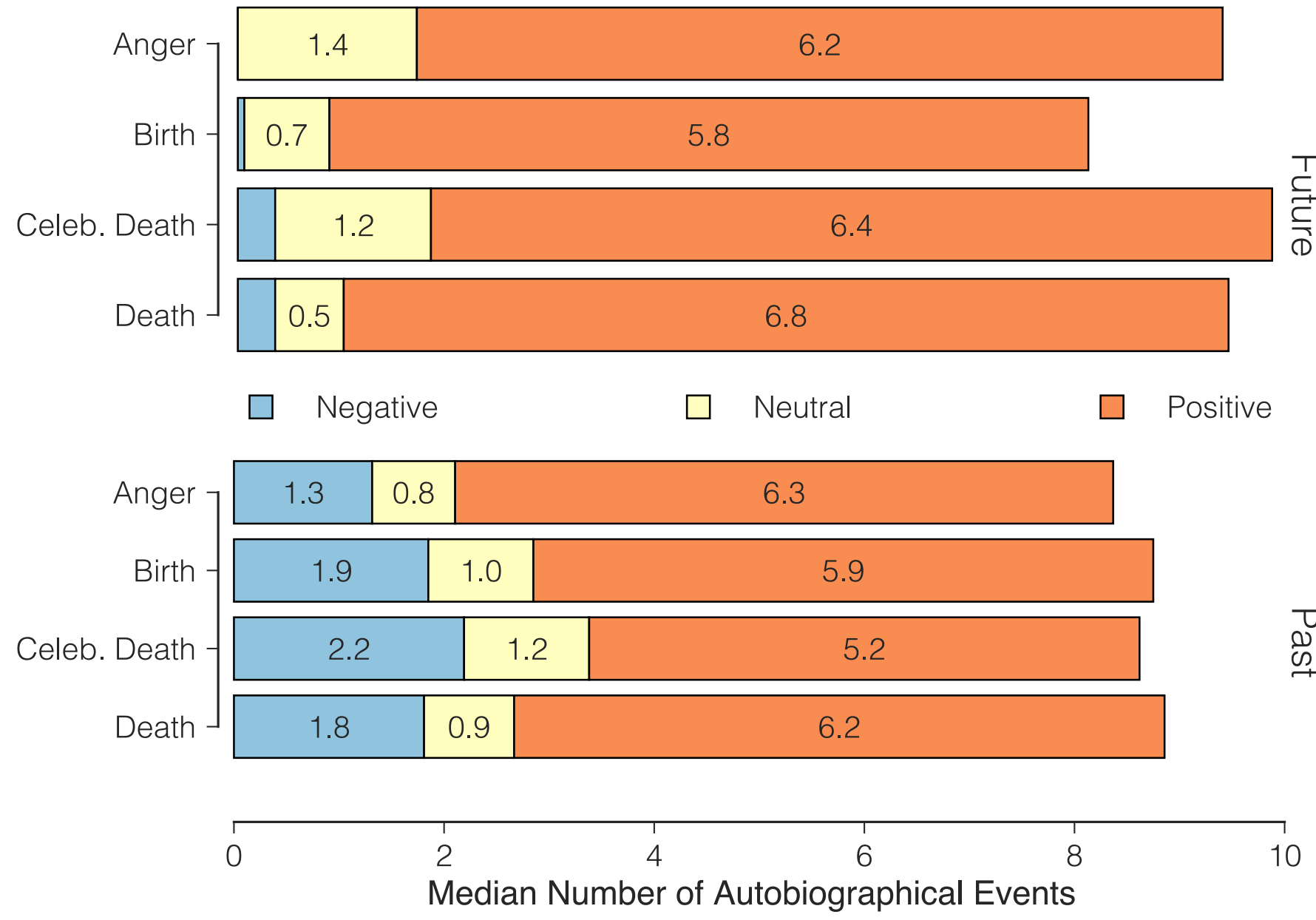

Figure 1. Autobiographical Fluency task. Median number of negative, neutral, and positive events generated during construction of past and future scenes. The distribution of negative, neutral and positive events is similar across condition within temporal contexts. Note that negative events are virtually absent for future episodes.

\section{Episodic specificity of temporal representations: Cueing}

Figure 2 displays the average across participants of the individual increase of past-related relative to future-related internal details in percent. It can be readily seen that in the Death condition change was consistently greater than zero percent, suggesting that individuals generated on average about $58 \%$ more frequently past as compared to future events. Contrastingly, no consistently changed past to future ratio was visible for the other conditions. 


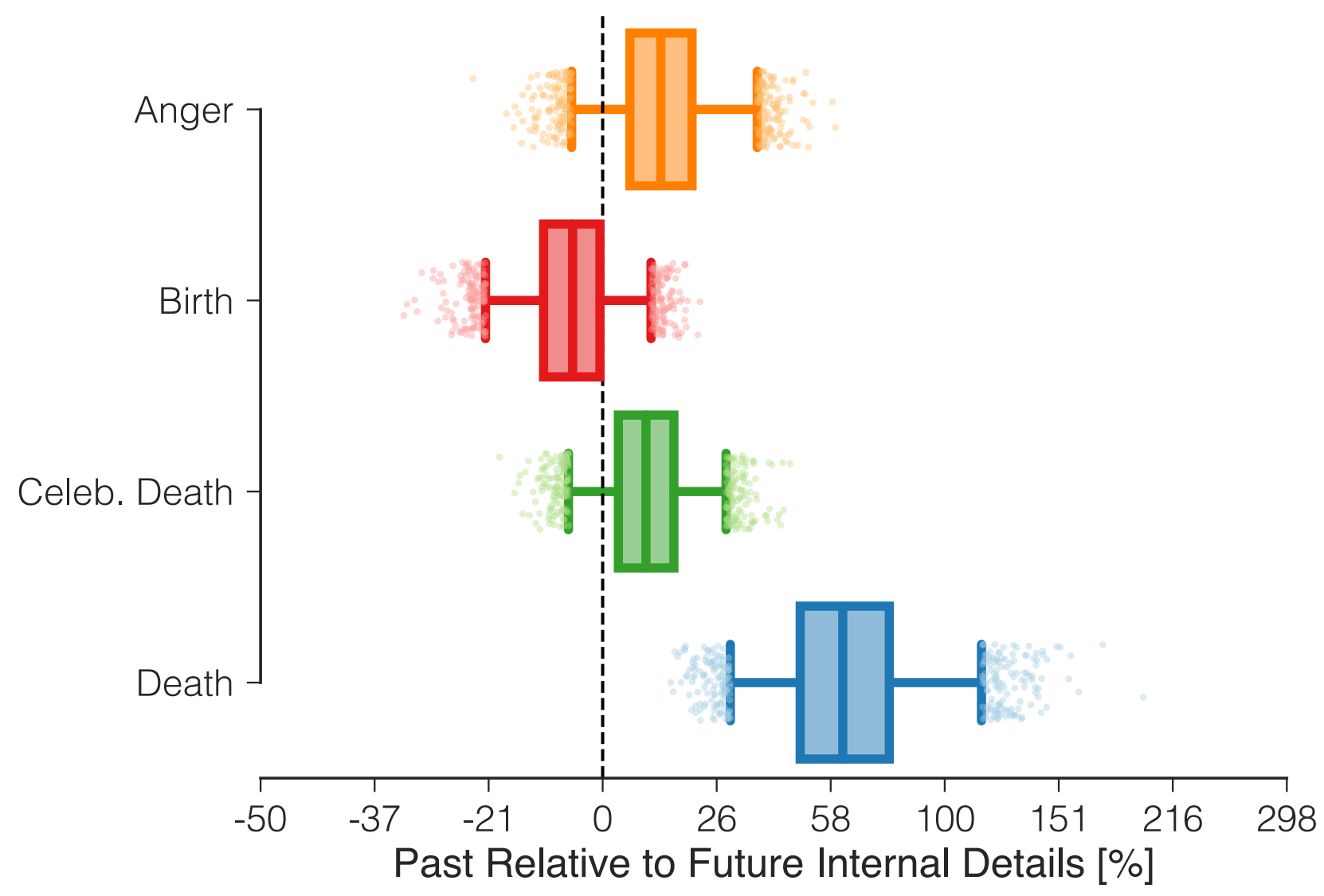

Figure 2. Cueing task. For each condition, here the average log ratio of past to future internal details is depicted. Values bigger than zero indicate more frequent reports of past-related than future-related details. The two-sided 95\% confidence intervals are indicated by the whiskers of each box plot. It can be readily seen that for the Death condition, the average log past to future ratio was significantly higher than zero and was subject to more variability.

In a second step, we explicitly modeled the number of internal details generated by participant (averaged across trials) as a function of the Condition, Temporal Direction, and their interaction, using a linear mixed-effect regression with participants entered as a random factor. First, this analysis suggested that participants generated more internal details for past events, $b=6.17, \mathrm{SE}=$ $1.74, \mathrm{p}<.001$. Second, the analysis revealed that participants generated less internal details in the Death condition than in any other condition: $b=11.62, \mathrm{SE}=2.72, \mathrm{p}<.001$ (vs. Celebrity Death); $b$ $=9.88, \mathrm{SE}=2.76, \mathrm{p}<.001$ (vs. Birth); $\mathrm{b}=6.01, \mathrm{SE}=2.80, \mathrm{p}<.05$ (vs. Anger). Third, this analysis detected interaction effects which suggest that the the Death condition had a preferential impact on 
the imagination of future as compared to past events events (except when compared to Anger): $b=$ 5.52, $\mathrm{SE}=2.46, \mathrm{p}<.05$ (vs. Celebrity Death); $\mathrm{b}=7.57, \mathrm{SE}=2.49, \mathrm{p}<.01$ (vs. Birth); $\mathrm{b}=3.11, \mathrm{SE}$ $=2.52$, ns (vs. Anger). It is noteworthy that the subjective experience during the imagined episodes was comparable between the conditions except for the visual clarity of the imagination which was consistently lower in the Death condition (See Supplementary Results on 'Cueing task: Subjective experience' and Supplementary Figure 3). To summarize, our analyses suggest that the richness and sharpness of imagined future episodes preferentially decreased when subjects had previously imagined their own death.

\section{Discussion}

In his seminal book, The Denial of Death, winner of the Pulitzer Prize, Ernest Becker (1973) maintained that if the individual "wants to feel a warm sense of inner value and basic security [...] he must repress $[\ldots]$ his fundamental expendability in nature" (p. 32). Indeed, individuals are prone to respond to threatening thoughts of death with more protective behaviours (Greenberg \& Arndt, 2011). In the present study, we suggest that one of these protective behaviours reflects in a specific reluctance to imagine future scenarios, but not past scenarios, after having vividly imagined one's own death. In contrast to previous theories, which maintain that individuals do not need to obsess on death, we suggest that instead individuals do not want to think of death because doing so would impair their ability to think about their future, hence, lead to maladaptive behaviour.

Importantly, this effect is not due to a reluctance to imagine negative episodes per se (i.e., episode of intense anger), to a conceptual awareness of death (i.e., death of a famous character), nor to the difficulty to imagine a never-thought-of episode (i.e., one's own birth). Moreover, the bias does not affect the accessibility of future thoughts, but only their specificity (i.e., number of internal details). This was demonstrated using two tasks: one assessing the accessibility of generic representations of the future, i.e., the Autobiographical Fluency task, adapted from D'Argembeau et al. (2010) and Neroni et al. (2016), the other assessing the episodic quality of future simulations, i.e., the Cueing task adapted from D'Argembeau and Van der Linden (2004) and from Addis, Wong, and Schacter (2008). The first task did not elicit any difference in the response time and in the quantity of future representations produced in the four conditions (i.e., no difference in accessibility). The Cueing task 
instead induced significant differences in the number of internal details produced in the experimental condition compared to the control conditions, selectively for future events (i.e., relevant difference in specificity). The same pattern was already evident when participants were required to describe in details the moment of their death, in the mortality salience manipulation. They did not have any problem to access this description, as shown by the normal response time. However, when it came to detail the description of this particular future event, the participants used more external details, suggesting that they intended to maintain a more disengaged scenario, rather than materialising it episodically.

The ability to simulate future events is one of the most distinctive and significant features of cognition, fundamental to prepare for future events. A simulation is by definition the construction of a specific (episodic) mental representation of the future (Schacter, Benoit, \& Szpunar, 2017). Episodic specificity, i.e., number of internal details produced, is an important measure to evaluate future events (Addis, Musicaro, Pan, \& Schacter, 2010; Addis, Wong, \& Schacter, 2008; Levine et al., 2002). A decreased amount of internal details in episodic future thinking has been observed in different clinical populations (e.g., Alzheimer's disease, Addis et al., 2009; aMCI, Gamboz et al., 2010; Parkinson's disease, de Vito et al., 2012b; Semantic dementia, Irish et al., 2012) and in healthy participants, whose cognitive abilities, such as spatial mental imagery, are experimentally disrupted (de Vito, 2012; de Vito et al., 2014; de Vito et al., 2015b). The production of internal details is typically also affected by aging (for a review, see Schacter, Gaesser, \& Addis, 2012). Such age-related changes in constructing the future have been correlated with episodic (e.g., memory deficits, Addis et al., 2008) and non-episodic factors (e.g., narrative style, Gaesser et al., 2011). It has been recently suggested that this lack of specificity of future representations represents part of a strategy to avoid uncomfortable future thoughts (Jumentier, Barsics, and Van der Linden, 2017). It may be that when asked to imagine their future, especially the distant future, older adults would be prone to access thoughts of death and they try to avoid this. They construct less episodic future thoughts, keeping a more semantic, hence less threatening scheme. Following this stream of literature, we demonstrated that a similar bias can also characterise younger adults when they intend to defend against conscious thoughts of their own's death. This coping is specifically adopted in future thinking, since it does not extend to past episodes. And it affects only the specificity of future events, having no impact on their accessibility. We suggest that this lack of specificity of future thoughts, after imagining one's own death, may be due to cognitive defenses to suppress thoughts of death. There are at least two possibilities to illustrate the nature of these cognitive strategies. 
One possibility is a cognitive distortion. After having been asked to imagine their own death, individuals become incline to reduce the interference of death-related thoughts on their subsequent future thinking. Our participants make their future representations more abstract to prevent the feeling of an immediate occurrence of their death. It is indeed not the abstract representation, but the simulation that increases the perceived realism of the imagined experience (e.g., Ernst \& D'Argembeau, 2017; Taylor \& Schneider, 1989). The ease of constructing in detail a particular simulation can be interpreted by the individual as an index of the probability of the occurrence of that simulation (Anderson \& Godfrey, 1987; Taylor \& Schneider, 1989). It has been also observed that the mere act of imagining oneself performing or not performing a certain behaviour can change expectations about oneself(Anderson \& Godfrey, 1987). The same does not apply to a generic representation of an event.

A second possibility is a depletion of cognitive resources used to suppress death-related thoughts from the current focal attention. The same would not apply to past thoughts, given that the future task requires more cognitive resources. Future thinking is more complex and places a higher demand on executive functions and dynamic mental manipulation of information than past task (e.g., Gamboz, Brandimonte, de Vito, 2010; Okuda et al., 2003; Suddendorf \& Corballis, 2007). In both cases, the result is a selective bias, which further shows that remembering the past and imagining the future are characterised by crucial differences (Schacter \& Addis, 2009). This happens not only because imagining the future requires a more extensive constructive processes relative to remembering (Schacter \& Addis, 2009), but also because the two processes can imply different motivations, hence different distortions. We remember the past to be able to anticipate the future, and we imagine the future to be prepared for the occurrence of plausible scenarios. Prospection gives us the possibility to act in the present to improve our future. When for some reasons, including thoughts of death, the future can become a threat, rather than a hope, we still access it, but we reduce its specificity. We access less detailed representations, relying on more disengaged schemes. We do not need to apply the ostrich bias to our past, but only to our future.

\section{Author contributions}


S. de Vito conceived the research; S. de Vito and S. Della Sala designed the research; M.A. Neroni and A. Capuozzo performed experiments; M.A. Neroni, J.F. Bonnefon, and D.A. Engemann analysed data; S. de Vito, J.F. Bonnefon, and D.A. Engemann interpreted the results of experiments; J.F. Bonnefon and D.A. Engemann prepared figures; S. de Vito drafted the manuscript; S. de Vito, M.A. Neroni, J.F. Bonnefon, M.A. Brandimonte, D.A. Engemann, and S. Della Sala edited and revised manuscript; S. de Vito, M.A. Neroni, J.F. Bonnefon, S. Della Sala, A. Capuozzo, D.A. Engemann, M.A. Brandimonte approved the final version of manuscript. 


\section{References}

Addis, D. R., Wong, A. T., \& Schacter, D. L. (2008). Age-related changes in the episodic simulation of future events. Psychological Science, 19(1), 33-41. http://dx.doi.org/10.1111/j. 1467-9280.2008.02043.x.

Addis, D. R., Sacchetti, D. C., Ally, B. A., Budson, A. E., \& Schacter, D. L. (2009). Episodic simulation of future events is impaired in mild Alzheimer's disease. Neuropsychologia, 47(12), 2660-2671. http://dx.doi.org/10.1016/j.neuropsychologia.2009.05.018

Addis, D. R., Musicaro, R., Pan, L., \& Schacter, D. L. (2010). Episodic simulation of past and future events in older adults: Evidence from an experimental recombination task. Psychology and Aging, 25(2), 369-376. http://dx.doi.org/10.1037/a0017280

Anderson, C.A. \& Godfrey, S.S. (1987). Thoughts about actions: The effects of specificity and availability of imagined behavioural scripts on expectations about oneself and others. Social Cognition, 3, 238-258.https://doi.org/10.1521/soco.1987.5.3.238.

Arndt, J., Greenberg, J., Solomon, S., Pyszczynski, T., \& Simon, L. (1997). Suppression, accessibility of death-related thoughts, and cultural worldview defense: Exploring the psychodynamics of terror management. Journal of Personality and Social Psychology, 73(1), 518. http://dx.doi.org/10.1037/0022-3514.73.1.5

Barca, L. and Burani, C. and Arduino, L. S. (2001). Una base di dati sui valori di età di acquisizione, frequenza, familiarità, immaginabilità, concretezza, e altre variabili lessicali e sublessicali per 626 nomi dell'Italiano. Giornale Italiano di Psicologia, 3, 839-856. http:// dx.doi.org/10.1421/379

Barsics, C., Van der Linden, M., \& D'Argembeau, A. (2016). Frequency, characteristics, and perceived functions of emotional future thinking in daily life. The Quarterly Journal of Experimental Psychology, 69(2), 217-233. http://dx.doi.org/10.1080/17470218.2015.1051560

Bates, D., Mächler, M., Bolker, B., \& Walker, S. (2014). Fitting linear mixed-effects models using lme4. arXiv preprint arXiv: 1406.5823.

Becker, E. (1973) The denial of death. New York: Free.

Berntsen, D., \& Bohn, A. (2010). Remembering and forecasting: The relation between autobiographical memory and episodic future thinking. Memory and Cognition, 38, 265-278. http://dx.doi.org/10.3758/MC.38.3.265.

Berntsen, D., \& Jacobsen, A. S. (2008). Involuntary (spontaneous) mental time travel into the past and future. Consciousness and Cognition, 17, 1093-1104. http://dx.doi.org/10.1016/ j.concog.2008.03.001

Burke, B. L., Martens, A., \& Faucher, E. H. (2010). Two decades of terror management theory: A meta-analysis of mortality salience research. Personality and Social Psychology Review, 14(2), 155-195. http://dx.doi.org/10.1177/1088868309352321 
D'Argembeau, A., \& Van der Linden, M. (2004). Phenomenal characteristics associated with projecting oneself back into the past and forward into the future: Influence of valence and temporal distance. Consciousness and cognition, 13(4), 844-858. http://dx.doi.org/10.1016/ j.concog.2004.07.007

D’Argembeau, A., Ortoleva, C., Jumentier, S., \& Van der Linden, M. (2010). Component processes underlying future thinking. Memory \& Cognition, 38(6), 809-819. http://dx.doi.org/ 10.3758/MC.38.6.809

de Vito, S., \& Della Sala, S. (2011). Predicting the future. Cortex, 47(8), 1018-1022. http:// dx.doi.org/10.1016/j.cortex.2011.02.020

de Vito, S., Gamboz, N., \& Brandimonte, M. A. (2012a). What differentiates episodic future thinking from complex scene imagery? Consciousness and Cognition, 21, 813-823. http:// dx.doi.org/10.1016/j.concog.2012.01.013

de Vito, S., Gamboz, N., Brandimonte, M. A., Barone, P., Amboni, M., \& Della Sala, S. (2012b). Future thinking in Parkinson's disease: An executive function?. Neuropsychologia, 50(7), 1494-1501. http://dx.doi.org/10.1016/j.neuropsychologia.2012.03.001

de Vito, S. (2012). The beyond within. Cortex, 48(6), 781-784. http://dx.doi.org/10.1016/j.cortex. 2011.09.008

de Vito, S., Buonocore, A., Bonnefon, J. F., \& Della Sala, S. (2014). Eye movements disrupt spatial but not visual mental imagery. Cognitive processing, 15(4), 543-549. http://dx.doi.org/ 10.1007/s10339-014-0617-1

de Vito, S., Neroni, M. A., Gamboz, N., Della Sala, S., \& Brandimonte, M. A. (2015a). Desirable and undesirable future thoughts call for different scene construction processes. The Quarterly Journal of Experimental Psychology, 68(1), 75-82. http://dx.doi.org/

$10.1080 / 17470218.2014 .937448$

de Vito, S., Buonocore, A., Bonnefon, J. F., \& Della Sala, S. (2015b). Eye movements disrupt episodic future thinking. Memory, 23(6), 796-805. http://dx.doi.org/

$10.1080 / 09658211.2014 .927888$

Ditto, P. H., Jemmot, J. B. \& Darley, J. M. (1988). Appraising the threat of illness: A mental representational approach. Health Psychology, 7, 183-200.

Efron, B., \& Hastie, T. (2016). Computer Age Statistical Inference (Vol. 5). Cambridge University Press.

Ernst, A., \& D'Argembeau, A. (2017). Make it real: Belief in occurrence within episodic future thought. Memory \& Cognition, 1-17. http://dx.doi.org/10.3758/s13421-017-0714-3.

Gaesser, B., Sacchetti, D. C., Addis, D. R., \& Schacter, D. L. (2011). Characterizing age-related changes in remembering the past and imagining the future. Psychology and aging, 26(1), 80. http://dx.doi.org/10.1037/a0021054

Gailliot, M. T., Schmeichel, B. J., \& Baumeister, R. F. (2006). Self-regulatory processes defend against the threat of death: Effects of self-control depletion and trait self-control on thoughts and 
fears of dying. Journal of Personality and Social Psychology, 91, 49-62. http://dx.doi.org/ 10.1037/0022-3514.91.1.49

Gamboz, N., Brandimonte, M. A., \& de Vito, S. (2010). The role of past in the simulation of autobiographical future episodes. Experimental psychology, 21(2), 813-823. https://doi.org/ $10.1027 / 1618-3169 / \mathrm{a} 000052$

Gamboz, N., de Vito, S., Brandimonte, M. A., Pappalardo, S., Galeone, F., Iavarone, A., \& Della Sala, S. (2010). Episodic future thinking in amnesic mild cognitive impairment.

Neuropsychologia, 48(7), 2091-2097. https://doi.org/10.1016/j.neuropsychologia.2010.03.030

Greenberg, J., Pyszczynski, T., \& Solomon, S. (1986). The causes and consequences of a need for self-esteem: A terror management theory. In R. F. Baumeister (Ed.), Public self and private self (pp. 189-212). New York: Springer-Verlag.

Greenberg, J., \& Arndt, J. (2011). Terror management theory. In P. A. M. Van Lange, A. W. Kruglanski (Eds.). Handbook of theories of social psychology, 1, (pp. 398-415). London: SAGE.

Irish, M., Addis, D. R., Hodges, J. R., \& Piguet, O. (2012). Considering the role of semantic memory in episodic future thinking: evidence from semantic dementia. Brain, 135(7), 2178-2191. https://doi.org/10.1093/brain/aws119

Jumentier, S., Barsics, C., \& Van der Linden, M. (2017). Reduced specificity and enhanced subjective experience of future thinking in ageing: the influence of avoidance and emotionregulation strategies. Memory, 1-15. http://dx.doi.org/10.1080/09658211.2017.1322108

Kant I. (1996). Anthropology from a Pragmatic Point of View. Trans. Victor Lyle Dowdell. Carbondale. Illinois: Southern University Press Paperback edition (originally published 1798).

Kunda, Z. (1987). Motivated inference: Self-serving generation and evaluation of causal theories. Journal of personality and social psychology, 53(4), 636-647. http://dx.doi.org/ 10.1037/0022-3514.53.4.636

Leopardi, G. (1831 - 1832). Dialogo di un venditore d'almanacchi e di un passeggere. In Operette Morali. Napoli: Starita Editore.

Levine, B., Svoboda, E., Hay, J. F., Winocur, G., \& Moscovitch, M. (2002). Aging and autobiographical memory: dissociating episodic from semantic retrieval. Psychology and aging, 17(4), 677. http://dx.doi.org/10.1037/0882-7974.17.4.677

Neroni, M. A., Gamboz, N., \& Brandimonte, M. A. (2014). Does episodic future thinking improve prospective remembering?. Consciousness and cognition, 23, 53-62. http://dx.doi.org/ 10.1016/j.concog.2013.12.001

Neroni, M. A., Gamboz, N., de Vito, S., \& Brandimonte, M. A. (2016). Effects of self-generated versus experimenter-provided cues on the representation of future events. The Quarterly Journal of Experimental Psychology, 69(9), 1799-1811. http://dx.doi.org/

10.1080/17470218.2015.1100205

Newby-Clark, I. R., Ross, M., Buehler, R., Koehler, D. J., \& Griffin, D. (2000). People focus on optimistic scenarios and disregard pessimistic scenarios while predicting task completion times. 
Journal of Experimental Psychology: Applied, 6, 171-182. http://dx.doi.org/10.1037/1076-898X. 6.3.171

Okuda, J., Fujii, T., Ohtake, H., Tsukiura, T., Tanji, K., Suzuki, K., ... \& Yamadori, A. (2003). Thinking of the future and past: The roles of the frontal pole and the medial temporal lobes. Neuroimage, 19(4), 1369-1380. https://doi.org/10.1016/S1053-8119(03)00179-4

R Core Team (2015). R: A language and environment for statistical computing. R Foundation for Statistical Computing, Vienna, Austria. URL https://www.R-project.org/.

Schacter, D. L., \& Addis, D. R. (2009). On the nature of medial temporal lobe contributions to the constructive simulation of future events. Philosophical Transactions of the Royal Society of London B: Biological Sciences, 364(1521), 1245-1253. http://dx.doi.org/10.1098/rstb.2008.0308.

Schacter, D. L., Gaesser, B., \& Addis, D. R. (2013). Remembering the past and imagining the future in the elderly. Gerontology, 59(2), 143-151. https://doi.org/10.1159/000342198

Schacter, D. L., Benoit, R. G., \& Szpunar, K. K. (2017). Episodic future thinking: mechanisms and functions. Current Opinion in Behavioral Sciences, 17, 41-50. http://dx.doi.org/10.1016/ j.cobeha.2017.06.002

Seligman, M. E., Railton, P., Baumeister, R. F., \& Sripada, C. (2016). Homo prospectus. Oxford University Press.

Sharot, T., Riccardi, A. M., Raio, C. M., \& Phelps, E. A. (2007). Neural mechanisms mediating optimism bias. Nature, 450(7166), 102. http://dx.doi.org/10.1038/nature06280

Sherman, S. J., Cialdini, R. B., Schwartzman, D. F., \& Reynolds, K. D. (1985). Imagining can heighten or lower the perceived likelihood of contracting a disease: The mediating effect of ease of imagery. Personality and Social Psychology Bulletin, 11, 118-127. http://dx.doi.org/ $10.1177 / 0146167285111011$.

Szpunar, K. K., \& Schacter, D. L. (2013). Get real: Effects of repeated simulation and emotion on the perceived plausibility of future experiences. Journal of Experimental Psychology: General, 142, 323-327. http://dx.doi.org/10.1037/a0028877

Suddendorf, T. \& Corballis, M.C. (2007). The evolution of foresight: What is mental time travel, and is it unique to humans?. Behavioural and brain sciences, 30(3), 299-351. https://doi.org/ $10.1017 / \mathrm{S} 0140525 \mathrm{X} 07001975$

Taylor, S. E., \& Schneider, S. K. (1989). Coping and the simulation of events. Social cognition, 7(2), 174-194. https://doi.org/10.1521/soco.1989.7.2.174

Trémolière, B., De Neys, W., \& Bonnefon, J. F. (2012). Mortality salience and morality: Thinking about death makes people less utilitarian. Cognition, 124(3), 379-384. http://dx.doi.org/10.1016/ j.cognition.2012.05.011.

Trémolière, B., De Neys, W., \& Bonnefon, J. F. (2014). The grim reasoner: Analytical reasoning under mortality salience. Thinking \& Reasoning, 20(3), 333-351. http://dx.doi.org/ 10.1080/13546783.2013.823888 
Weinstein, N. D. (1980). Unrealistic optimism about future life events. Journal of Personal and Social Psychology, 39, 806-820. http://dx.doi.org/10.1037/0022-3514.39.5.806 